\title{
Article \\ A Portable Biodevice to Monitor Salivary Conductivity for the Rapid Assessment of Fluid Status
}

\author{
Chun-Hao Chen ${ }^{1,+}{ }^{\dagger}$, Yen-Pei Lu ${ }^{2,+}$, An-Ting Lee ${ }^{3}$, Chun-Wu Tung ${ }^{4,5}$, Yuan-Hsiung Tsai ${ }^{6}$, Hsin-Pei Tsay ${ }^{7}$, \\ Chih-Ting Lin ${ }^{8, *}$ and Jen-Tsung Yang ${ }^{7,9, *}$
}

1 Department of Orthopedic Surgery, Chang Gung Memorial Hospital, Chiayi 61363, Taiwan; a0983109189@gmail.com

2 Taiwan Instrument Research Institute, National Applied Research Laboratories, Hsinchu 30261, Taiwan; ypl@narlabs.org.tw

3 Department of Anesthesiology, Chang Gung Memorial Hospital, Chiayi 61363, Taiwan; annielee@cgmh.org.tw

4 Department of Nephrology, Chang Gung Memorial Hospital, Chiayi 61363, Taiwan; P122219@cgmh.org.tw

5 Graduate Institute of Clinical Medical Sciences, Chang Gung University, Taoyuan 33302, Taiwan

6 Department of Diagnostic Radiology, Chang Gung Memorial Hospital, Chiayi 61363, Taiwan; russell.tsai@gmail.com

7 Department of Neurosurgery, Chang Gung Memorial Hospital, Chiayi 61363, Taiwan; thp191108@gmail.com 8 Graduate Institute of Electrical Engineering, National Taiwan University, Taipei 10617, Taiwan

9 College of Medicine, Chang Gung University, Taoyuan 33302, Taiwan

* Correspondence: timlin@ntu.edu.tw (C.-T.L.); jents716@icloud.com (J.-T.Y.); Tel.: +886-(0)2-3366-9604 (C.-T.L.); +886-(0)5-362-1000 (J.-T.Y.)

+ Both authors contributed equally to this work and are listed as co-first authors.

Citation: Chen, C.-H.; Lu, Y.-P.; Lee, A.-T.; Tung, C.-W.; Tsai, Y.-H.; Tsay,

H.-P.; Lin, C.-T.; Yang, J.-T. A Portable Biodevice to Monitor Salivary

Conductivity for the Rapid Assessment of Fluid Status. J. Pers. Med. 2021, 11, 577. https://doi.org/ $10.3390 /$ jpm 11060577

Academic Editor: Pascale Gauthier

Received: 23 May 2021

Accepted: 17 June 2021

Published: 19 June 2021

Publisher's Note: MDPI stays neutral with regard to jurisdictional claims in published maps and institutional affiliations.

Copyright: (C) 2021 by the authors Licensee MDPI, Basel, Switzerland. This article is an open access article distributed under the terms and conditions of the Creative Commons Attribution (CC BY) license (https:/ / creativecommons.org/licenses/by/ $4.0 /)$.

\begin{abstract}
The evaluation of fluid status can save adults from life-threatening conditions, but the current methods are invasive or time-consuming. Therefore, we developed a portable device for measuring salivary conductivity. This prospective observational study enrolled 20 volunteers with no history of systemic diseases. Participants were observed for $13 \mathrm{~h}$, including water restriction for $12 \mathrm{~h}$ followed by rehydration with $1000 \mathrm{~mL}$ water within $1 \mathrm{~h}$. Serum and urine biomarkers for fluid status, thirst scales, and salivary conductivity were collected during dehydration and rehydration. No significant differences in age, body mass index, glycohemoglobin, and estimated glomerular filtration rate were noted between sexes. Salivary conductivity increased after water restriction and decreased after rehydration. Similarly, urine osmolality, urine specific gravity, thirst intensity scales, and body weight followed the same trend and were statistically significant. The angiotensin-converting enzyme and aldosterone levels showed the same trend, without reaching statistical significance. The red blood cell count and hemoglobin concentration also followed the same trend. Analyzing the receiver operating characteristic curves, the area under the curve was 0.707 (95\% confidence interval $0.542-0.873, p=0.025)$. Using the Youden index, the optimal cutoff determined as $2678.09 \mu \mathrm{s} / \mathrm{cm}$ (sensitivity: $90 \%$, specificity: $55 \%$ ). This biodevice effectively screened dehydration among healthy adults.
\end{abstract}

Keywords: salivary conductivity; fluid status; portable biodevice

\section{Introduction}

The regulation of fluid status is a complicated process that is meticulously conducted by the human body. The massive loss of body fluid can lead to an imbalance in fluid status and can sometimes progress to dehydration. Progressive negative changes in fluid status can directly affect many organ systems and cause life-threatening circulatory failure in severe clinical conditions [1]. Friedrich et al. [2] reported that dehydration is associated with a higher risk of disability and mortality among the elderly. It has also been described as a risk factor for falls in older adults and is considered a key factor associated with the 
performance of soccer athletes under stress [3,4]. Cognitive function and performance have been shown to improve after adequate water supplementation after dehydration $[5,6]$. Furthermore, several clinical studies have revealed that dehydration is highly related to mortality and morbidity [7-9]. However, early fluid imbalance may not result in obvious clinical symptoms, and an individual with dehydration may be asymptomatic before the onset of critical disease. Therefore, the early detection of fluid imbalance is important to prevent subsequent deterioration of the clinical condition.

The balance and disorders of water and electrolytes have central roles in the clinical conditions related to fluid status. Medical history and physical examination have been used for diagnosis of dehydration. However, both clinical history and physical examination cannot diagnose dehydration validly. Medical history can provide information of possible water depletion but cannot provide quantitative data objectively. Physical examination has been reported to not be valid in clinical practice due to its poor sensitivity in detection of dehydration [10-12]. Currently, several blood and urine biomarkers are being used for the evaluation of dehydration. Serum osmolality can indicate euvolemia based on the objective normal range of serum tonicity (275-295 mOsm $/ \mathrm{kg}$ of water). Urine specific gravity and osmolality have also been reported as valid biomarkers for the evaluation of fluid status $[13,14]$. However, in clinical practice, continuous monitoring of serum osmolality is not feasible because of its invasiveness. Meanwhile, although the collection of urine specimens is simple and non-invasive, urine voiding is not available at any time. Additionally, extreme dehydration reduces the amount of urine, making the collection of urine more difficult. This limits the practicality of urine testing. Several clinical studies have used other non-invasive biomarkers, such as sweat and tears, for the evaluation of fluid status [15]. However, sweat collection is time-consuming and is limited to sweating participants. Conversely, the collection of tear specimens is affected by evaporation and differences in the collection methods [16].

In contrast, saliva can be collected directly using a simple method that does not require specific equipment and can be performed even in a non-clinical setting, making it a feasible option. Most importantly, saliva collection is a non-invasive procedure. Salivary conditions can reflect fluid status after fluid intake and stabilize within half a minute [17].

We recently developed a novel device for measuring saliva conductivity, which has been found to be associated with fluid status [18]. Data on saliva conductivity can be acquired immediately using a portable monitor system, which allows for a non-invasive and real-time evaluation of fluid status. This pilot study aimed to confirm the correlation between salivary conductivity and fluid status with acute dehydration and rehydration in healthy participants.

\section{Materials and Methods}

\subsection{Ethical Statement}

This longitudinal observational study complied with the guiding principles of the Declaration of Helsinki and was approved by the Medical Ethics Committee of Chang Gung Memorial Hospital (institutional review board number: 201700651B0). Before the study, all subjects signed an informed consent form.

\subsection{Subjects}

Twenty healthy adults aged 18 years and above volunteered to participate in the study. They received regular annual health examinations at Chiayi Chung Gang Memorial Hospital. They were all non-smokers with no oral, dental, or systemic diseases during the study. Systemic disease concerned in this study any cardiovascular disease, peripheral vascular disease, renal disease, hepatic disease, infection episode and endocrine disease. They also did not take any prescription or over-the-counter medications during the study. The power of this study is $80 \%$ with a hypothetical effect size of 0.6 . The required sample would be 20 participants. Post hoc computing of the power of study and effect size of all the outcomes was performed using the G-power statistical software. 


\subsection{Experimental Procedures}

We explained the experimental design to all participants before the study, including saliva collection, hematological and biochemical examination, body composition analysis, and evaluation of thirst scale. Data collection was conducted at three continuous time points: at the beginning of the study, after $12 \mathrm{~h}$ of water restriction, and at $1 \mathrm{~h}$ after rehydration with $1000 \mathrm{~mL}$ of water. In this study, the participants were prohibited from drinking any fluid and eating food containing more than $500 \mathrm{~mL}$ fluid for $12 \mathrm{~h}$ to achieve a dehydration status. There was no limitation of their physical activities and the status of dehydration was confirmed by serum and urinary analysis after $12 \mathrm{~h}$.

\subsection{Saliva Collection and Analysis}

Saliva specimens of all volunteers were collected orally at least $1 \mathrm{~h}$ after any intake. Saliva samples were assessed with a portable conductivity meter and a sensing probe, which were designed and fabricated as described in a previous study [18]. The miniaturized sensing electrode was placed in horizontally parallel and its sample-contact area reduced. Hence, the required amount of saliva was reduced to $50-500 \mu \mathrm{L}$ for a test. The conductivity meter was pre-calibrated with the standard conductivity solution prior to the clinical study. Saliva samples were applied to the well of the sensing probe that was connected through a USB port to the conductivity meter, which immediately read the data (Figure 1).

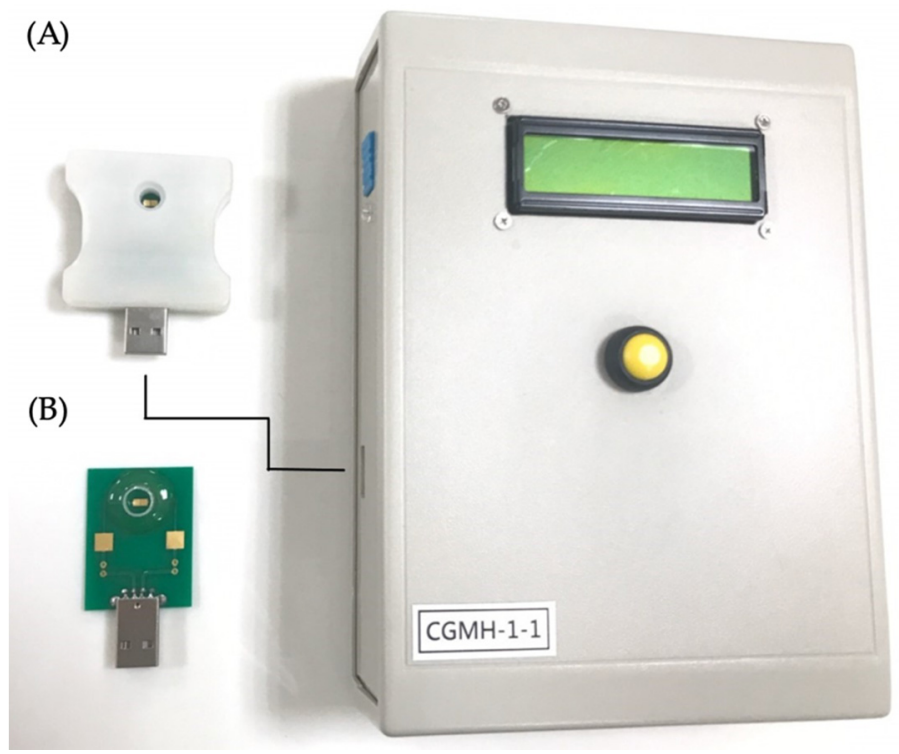

Figure 1. Measuring of salivary conductivity with the portable biodevice. (A) Salivary samples were applied to the well of the sensing probe. The sensing probe was connected to the conductivity meter through a USB port and read out the data immediately after pressing the yellow button. (B) The disposable printed-circuit board (PCB )of the sensing probe inside the shelter and the electrode were placed in horizontally parallel.

Saliva specimens were collected according to the following steps (Figure 2):

1. The participant swallowed to empty their mouth.

2. Saliva was collected with a 1-mL dropper, and the collected salivary sample was placed in a $1.5 \mathrm{~mL}$ Eppendorf tube.

3. The saliva sample $(100 \mu \mathrm{L})$ was then diluted with $100 \mu \mathrm{L}$ of deionized water.

4. Saliva conductivity was then analyzed using the developed portable monitor with a disposable printed-circuit board (PCB) electrode.

5. Data on salivary conductivity was then recorded. 


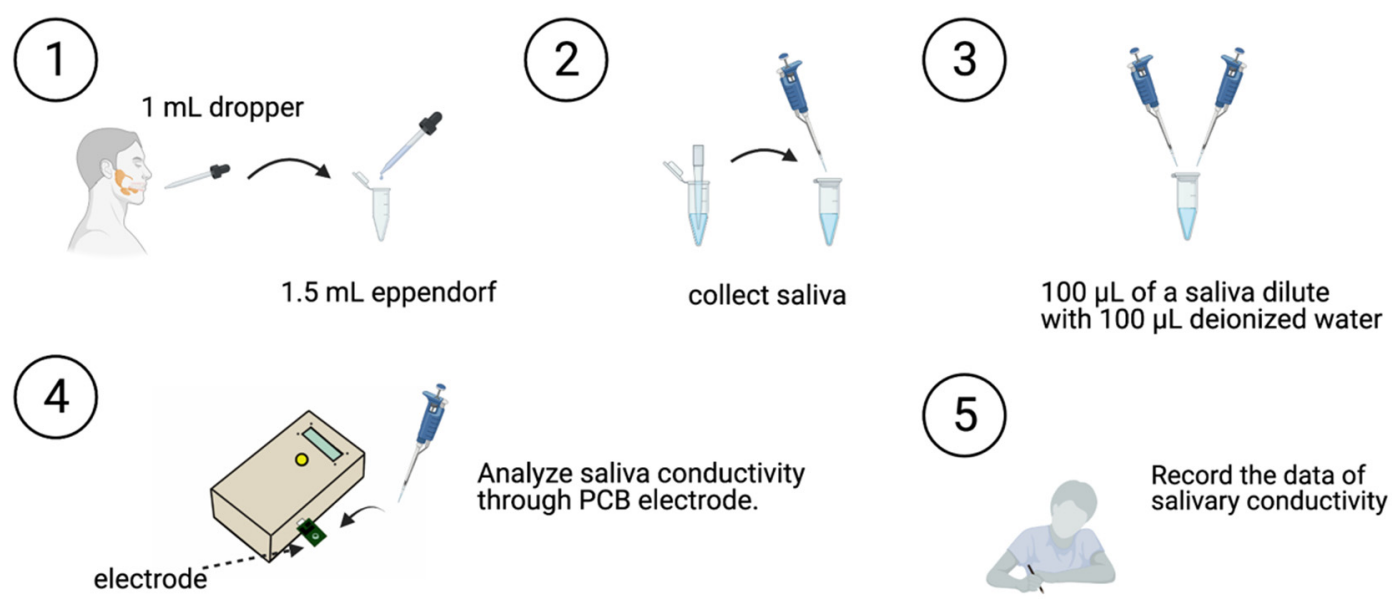

Figure 2. The salivary collection and analysis protocol. Salivary conductivity is detected using a printed-circuit board biodevice. (1): Saliva was collected with a 1-mL dropper. (2): The collected salivary sample was placed in a $1.5 \mathrm{~mL}$ Eppendorf tube. (3): The saliva sample $(100 \mu \mathrm{L})$ was then diluted with $100 \mu \mathrm{L}$ of deionized water. (4): Saliva conductivity was then analyzed using the developed portable monitor with a disposable printed-circuit board (PCB) electrode. (5): Data on salivary conductivity was then recorded.

\subsection{Blood and Urine Collection and Analysis}

Blood samples were collected from a vein in the non-dominant hand. All laboratory values, including blood cell count, biochemical data, and copeptin, were analyzed using automated and standardized methods. Urine samples were collected into universal containers and analyzed with standard laboratory methods using an automatic analyzer (SYSMEX-XN9000, Japan; Beckman Coulter-DXC800, Trinity-Premier HB9210, and Advanced Instruments-Osmometer Model 3250, U.S.A; FUJIREBIO-FR-ACE color and ELISA Reader: TECAN Sunrise, Austria). Serum copeptin was analyzed using the Human Copeptin CPP ELISA Kit (P01185 (UniProt, ExPASy)), Abbexa LLC, Houston, TX, USA.

\subsection{Evaluation of the Thirst Intensity Scales}

Two thirst intensity scales were utilized in this study: the categorical scale and visual analog scale $[19,20]$. The categorical scale reflects the participants' thirst intensity through seven options, while the visual analog scale uses a linear scale with a range of 0-100 $\mathrm{mm}$.

\subsection{Statistical Analysis}

Continuous variables are presented as the mean \pm standard deviation. For comparison between the two groups, the Wilcoxon signed-rank test was used for quantitative variables. The Friedman test was used to compare data among the baseline, water restriction, and rehydration groups. Receiver operating characteristic (ROC) curve analysis was used to quantify the accuracy of medical diagnostic tests among the different groups. The criterion value was determined using the Youden index [21]. The criterion for rejecting the null hypothesis was the $95 \%$ confidence interval. Statistical analysis was performed using the Statistical Program for the Social Sciences version 25 (IBM Corporation, Armonk, NY, USA) for Macintosh.

\section{Results}

\subsection{Demographics of the Participants}

This study included 20 voluntary participants from the Chiayi Chang Gung Memorial Hospital (Table 1). The participants were aged $35.15 \pm 4.09$ years. The males and females had a body height of $175.03 \pm 4.06 \mathrm{~cm}$ and $162.33 \pm 8.25 \mathrm{~cm}(p=0.000)$, respectively, and a body weight of $76.84 \pm 10.80 \mathrm{~kg}$ and $61.89 \pm 14.62 \mathrm{~kg}(p=0.011)$, respectively. There was no statistically significant difference between the male and females in the body mass index ( $25.07 \pm 3.30$ vs. $23.37 \pm 3.99$, respectively; $p=0.123)$. Laboratory data of estimated 
glomerular filtration rate and glycohemoglobin levels were within the normal ranges in all participants.

Table 1. Baseline characteristics of the healthy participants, stratified by sex $(n=20)$.

\begin{tabular}{ccccc}
\hline Variables & $\begin{array}{c}\text { All patients } \mathbf{( N} \\
\mathbf{2 0})\end{array}$ & Male $\mathbf{( N = 1 0 )}$ & Female $(\mathbf{N}=\mathbf{1 0})$ & $p$ Value \\
\hline Age, years & $35.15 \pm 4.09$ & $35.50 \pm 4.48$ & $34.80 \pm 3.88$ & 0.684 \\
\hline $\mathrm{HbA1c}, \%$ & $5.43 \pm 0.26$ & $5.43 \pm 0.29$ & $5.43 \pm 0.25$ & 0.280 \\
\hline $\begin{array}{c}\mathrm{eGFR}, \\
\mathrm{mL} / \mathrm{min} / 1.73 \\
\mathrm{~m}^{2}\end{array}$ & $96.12 \pm 16.67$ & $91.70 \pm 16.90$ & $100.54 \pm 16.04$ & 0.912 \\
\hline Height, $\mathrm{cm}$ & $168.68 \pm 9.08$ & $175.03 \pm 4.06$ & $162.33 \pm 8.25$ & $0.000^{* * *}$ \\
\hline Weight, $\mathrm{kg}$ & $69.37 \pm 14.67$ & $76.84 \pm 10.80$ & $61.89 \pm 14.62$ & $0.011^{*}$ \\
\hline BMI, $\mathrm{kg} / \mathrm{m}^{2}$ & $24.22 \pm 3.67$ & $25.07 \pm 3.30$ & $23.37 \pm 3.99$ & 0.123 \\
\hline
\end{tabular}

Note: Values are shown as the mean \pm standard deviation. Abbreviations: BMI: body mass index. eGFR: estimated glomerular filtration rate. HbA1c: glycosylated hemoglobin. Note: ${ }^{*} p<0.05,{ }^{* * *} p<0.001$

\subsection{Biochemical, Urinary, and Hematological Data}

Table 2 shows the biochemical parameters, urinary analysis, and hematological parameters in the three different study phases. The urine creatinine and urine sodium levels increased after water restriction and decreased after rehydration with $1000 \mathrm{~mL}$ of water. The concentration of red blood cell count and hemoglobin showed the same trend as the results of the urinary analysis.

Table 2. Laboratory findings in the different groups (normal status, water restriction, and rehydration status).

\begin{tabular}{|c|c|c|c|c|}
\hline Variables & $\begin{array}{c}\text { Baseline } \\
\text { (Day 1, } 0600 \text { p.m.) }\end{array}$ & $\begin{array}{c}\text { 12-h } \\
\text { Water Restriction } \\
\text { (Day 1, 06:00 p.m. to } \\
\text { Day 2, 06:00 a.m.) }\end{array}$ & $\begin{array}{c}\text { 1-h } \\
\text { Water Rehydration } \\
\text { (Day 2, 06:00 a.m. to } \\
\text { Day 2, 07:00 a.m.) }\end{array}$ & $p$ Value \\
\hline \multicolumn{5}{|c|}{ Biochemical parameters } \\
\hline $\begin{array}{l}\text { Blood urea nitrogen, } \\
\text { mg/dL }\end{array}$ & $11.63 \pm 1.95$ & $11.17 \pm 2.11$ & $10.89 \pm 1.82$ & 0.279 \\
\hline $\begin{array}{l}\text { Creatinine, } \\
\text { mg/dL }\end{array}$ & $0.8335 \pm 0.18$ & $0.8240 \pm 0.16$ & $0.7835 \pm 0.17$ & $0.001^{* * *}$ \\
\hline $\begin{array}{l}\text { Sodium, } \\
\mathrm{mEq} / \mathrm{L}\end{array}$ & $141.15 \pm 2.08$ & $141.95 \pm 1.82$ & $140.05 \pm 1.99$ & $0.001^{* * *}$ \\
\hline $\begin{array}{c}\text { eGFR, } \\
\mathrm{mL} / \mathrm{min} / 1.73 \mathrm{~m}^{2}\end{array}$ & $96.12 \pm 16.67$ & $96.35 \pm 13.32$ & $103.10 \pm 17.11$ & $0.001^{* * *}$ \\
\hline $\begin{array}{l}\text { Serum glucose, } \\
\text { mg/dL }\end{array}$ & $93.45 \pm 14.04$ & $84.10 \pm 8.84$ & $85.80 \pm 10.27$ & $0.010^{* *}$ \\
\hline $\mathrm{HbA} 1 \mathrm{c}, \%$ & $5.43 \pm 0.26$ & $5.42 \pm 0.26$ & $5.42 \pm 0.24$ & 0.815 \\
\hline $\mathrm{eAG}, \mathrm{mg} / \mathrm{dL}$ & $109.2 \pm 7.46$ & $108.70 \pm 7.51$ & $108.90 \pm 6.77$ & 0.815 \\
\hline \multicolumn{5}{|c|}{ Urinary analysis } \\
\hline $\begin{array}{l}\text { Urine creatinine, } \\
\mathrm{mg} / \mathrm{dL}\end{array}$ & $87.59 \pm 81.39$ & $206.80 \pm 96.26$ & $22.96 \pm 21.68$ & $0.000^{* * *}$ \\
\hline $\begin{array}{l}\text { Urine sodium, } \\
\mathrm{mEq} / \mathrm{L}\end{array}$ & $94.9 \pm 50.08$ & $117.55 \pm 46.98$ & $28.55 \pm 21.05$ & $0.001^{* * *}$ \\
\hline \multicolumn{5}{|c|}{ Hematological parameters } \\
\hline RBC count, $1000 / \mathrm{uL}$ & $4.92 \pm 0.66$ & $5.01 \pm 0.64$ & $4.94 \pm 0.74$ & 0.014 * \\
\hline Hemoglobin, g/dL & $13.90 \pm 1.40$ & $14.18 \pm 1.51$ & $13.96 \pm 1.66$ & $0.018^{*}$ \\
\hline Hematocrit, $\%$ & $41.19 \pm 3.57$ & $42.00 \pm 4.00$ & $41.23 \pm 4.26$ & $0.002^{* *}$ \\
\hline
\end{tabular}

Note: Values are shown as the mean \pm standard deviation (SD). Abbreviations: eAG: estimated average glucose. eGFR: estimated glomerular filtration rate. HbA1c: glycosylated hemoglobin. RBC count: red blood cell count. Note: ${ }^{*} p<0.05,{ }^{* *} p<0.01{ }^{* * *} p<0.001$. 


\subsection{Trends of the Different Biomarkers and Parameters in Changing Fluid Status}

Compared with the group with a normal status (Figure 3), laboratory data in the group with a 12-h water restriction revealed increased salivary conductivity $(3671.445 \pm 1161.93 \mu \mathrm{s} / \mathrm{cm}$ vs. $3263.141 \pm 1140.30 \mu \mathrm{s} / \mathrm{cm}, p=0.018)$, serum osmolality $\left(293.25 \pm 4.30 \mathrm{mOsm} / \mathrm{kgH}_{2} \mathrm{O}\right.$ vs. $\left.290.35 \pm 4.08 \mathrm{mOsm} / \mathrm{kgH}_{2} \mathrm{O}, p=0.007\right)$, urine osmolality $\left(787.80 \pm 200.00 \mathrm{mOsm} / \mathrm{kgH}_{2} \mathrm{O}\right.$ vs. $\left.451.95 \pm 243.96 \mathrm{mOsm} / \mathrm{kgH}_{2} \mathrm{O}, p=0.001\right)$, urine specific gravity $(1.02 \pm 0.01$ versus $1.01 \pm 0.01, p=0.000)$, fraction excretion of sodium $(0.38 \pm 0.20 \%$ vs. $0.92 \pm 0.45 \%, p=0.001)$ and serum copeptin level $(254.31 \pm 100.05 \mathrm{pg} / \mathrm{mL}$ vs. $221.56 \pm 89.87 \mathrm{pg} / \mathrm{mL}, p=0.001)$. After rehydration with $1000 \mathrm{~mL}$ of water, all the levels of the biomarkers mentioned above decreased significantly (Table 3). The same trend was noted in the levels of angiotensinconverting enzyme and aldosterone, but the difference was not statistically significant. The results of the categorical and visual analog scales for thirst intensity significantly differed among the three groups. The serum copeptin levels were not significantly different between the water restriction and rehydration groups. The same clinical trend in different parameters for evaluation of fluid status was observed in different sexes, respectively (Tables S1-S3).
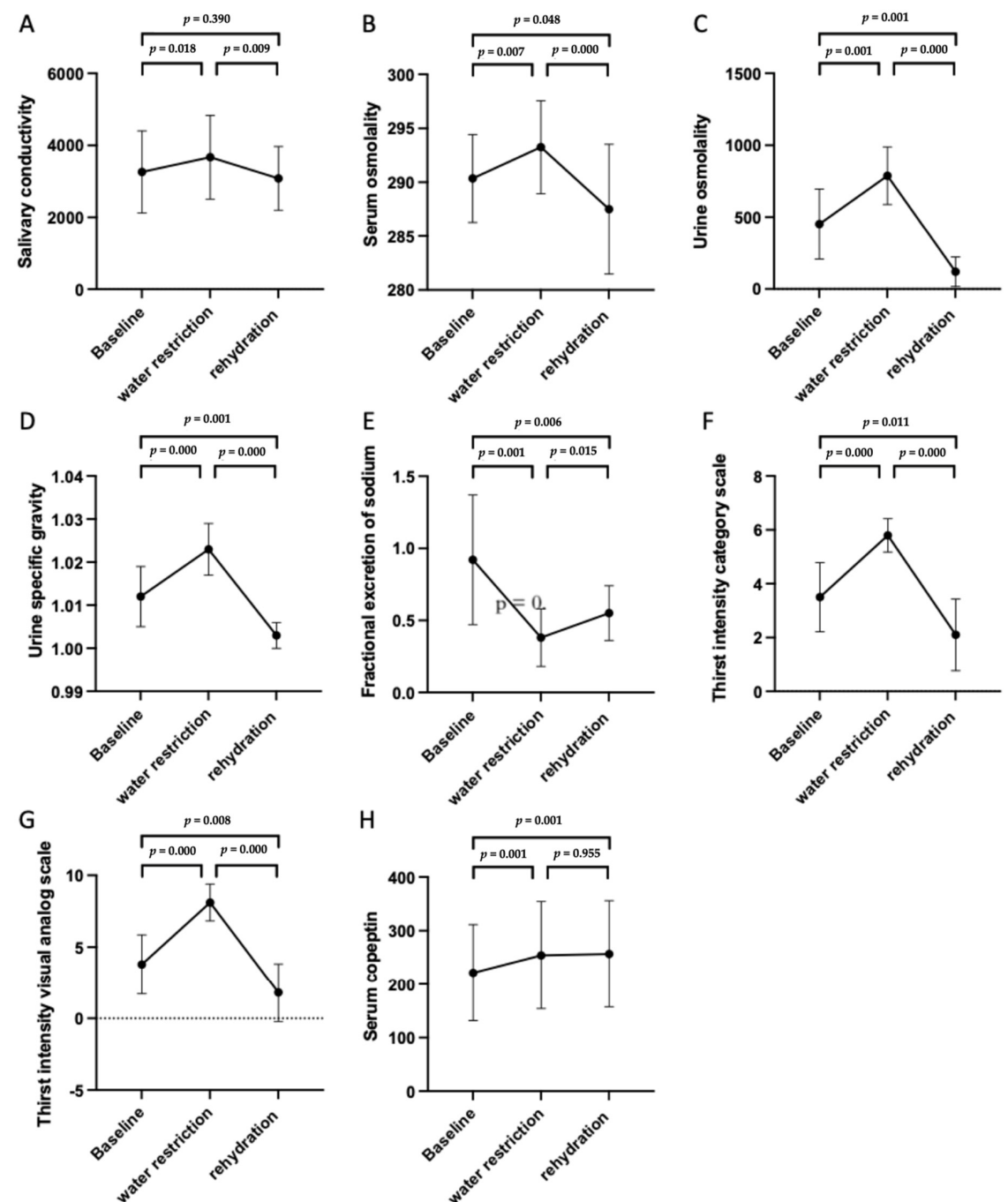

Figure 3. Changes in different biomarkers and parameters for evaluation of fluid status. The changes in the different biomarkers are shown with polygonal line graphs $(n=20)$, including salivary conductivity (A), serum osmolality (B), urine osmolality (C), urine specific gravity (D), fractional excretion of sodium (E), thirst intensity category scale (F), thirst intensity visual analog scale (G), and serum copeptin $(\mathbf{H})$. Note: The black dots and error bars indicate the mean and standard deviation of the biomarkers. The $p$-values between two different fluid statuses are labeled in each figure. 
Table 3. Different parameters for the evaluation of body fluid status.

\begin{tabular}{|c|c|c|c|c|}
\hline Variables & $\begin{array}{c}\text { Baseline } \\
\text { (Day 1, 06:00 p.m.) }\end{array}$ & $\begin{array}{c}\text { 12-h } \\
\text { Water Restriction } \\
\text { (Day 1, 06:00 p.m. to } \\
\text { Day 2, 06:00 a.m.) }\end{array}$ & $\begin{array}{c}\text { 1-h } \\
\text { Water Rehydration } \\
\text { (Day 2, } 0600 \text { a.m. to Day 2, } \\
\text { 07:00 a.m.) }\end{array}$ & $p$ Value \\
\hline $\begin{array}{l}\text { Salivary conductivity, } \\
\mu \mathrm{s} / \mathrm{cm}\end{array}$ & $3263.141 \pm 1140.30$ & $3671.445 \pm 1161.93$ & $3081.006 \pm 884.62$ & $0.019 *$ \\
\hline $\begin{array}{l}\text { Serum osmolality, } \\
\mathrm{mOsm} / \mathrm{kgH}_{2} \mathrm{O}\end{array}$ & $290.35 \pm 4.08$ & $293.25 \pm 4.30$ & $287.50 \pm 6.02$ & $0.000^{* * *}$ \\
\hline $\begin{array}{l}\text { Urine Osmolality, } \\
\mathrm{mOsm} / \mathrm{kgH}_{2} \mathrm{O}\end{array}$ & $451.95 \pm 243.96$ & $787.80 \pm 200.00$ & $119.20 \pm 102.25$ & $0.000 * * *$ \\
\hline Urine SG & $1.012 \pm 0.007$ & $1.023 \pm 0.006$ & $1.003 \pm 0.003$ & $0.000 * * *$ \\
\hline Thirst intensity CS & $3.50 \pm 1.28$ & $5.80 \pm 0.62$ & $2.10 \pm 1.33$ & $0.000^{* * *}$ \\
\hline Thirst intensity VAS & $3.79 \pm 2.07$ & $8.11 \pm 1.28$ & $1.80 \pm 2.02$ & $0.000 * * *$ \\
\hline $\begin{array}{l}\text { Serum copeptin, } \\
\mathrm{pg} / \mathrm{mL}\end{array}$ & $221.56 \pm 89.87$ & $254.31 \pm 100.05$ & $256.74 \pm 99.24$ & $0.001^{* *}$ \\
\hline $\mathrm{FeNa}, \%$ & $0.92 \pm 0.45$ & $0.38 \pm 0.20$ & $0.55 \pm 0.19$ & $0.000 * * *$ \\
\hline Weight, kg & $69.37 \pm 14.67$ & $76.84 \pm 10.80$ & $61.89 \pm 14.62$ & $0.011 *$ \\
\hline ACE test, IU/L & $15.35 \pm 4.10$ & $15.81 \pm 4.01$ & $15.48 \pm 3.91$ & 0.779 \\
\hline Aldosterone, ng/dL & $10.877 \pm 8.17$ & $11.37 \pm 6.77$ & $10.32 \pm 5.87$ & 0.861 \\
\hline Renin, ng/L & $18.196 \pm 13.79$ & $16.25 \pm 8.76$ & $14.75 \pm 7.03$ & 0.287 \\
\hline
\end{tabular}

Note: Values are shown as the mean \pm standard deviation (SD). Abbreviations: ACE test: angiotensin-converting enzyme test. FeNa: fractional excretion of sodium. Thirst intensity CS: thirst intensity categorical scale. Thirst intensity VAS: thirst intensity visual analog scale. Urine SG: urine specific gravity. Note: ${ }^{*} p<0.05,{ }^{* *} p<0.01,{ }^{* * *} p<0.001$.

\subsection{Use of Salivary Conductivity as a Screening Biomarker in Patients with Body} Fluid Deprivement

The ROC curve analysis of the salivary conductivity data of the 20 participants (AUC $=0.707$, $95 \%$ confidence interval $0.542-0.873, p=0.025$ ) (Figure 4 ) revealed that salivary conductivity had a good sensitivity in distinguishing between the body fluid status during water restriction and rehydration. The optimal salivary conductivity criterion value was $2678.09 \mu \mathrm{s} / \mathrm{cm}$, which had a sensitivity and specificity of $90 \%$ and $55 \%$, respectively.

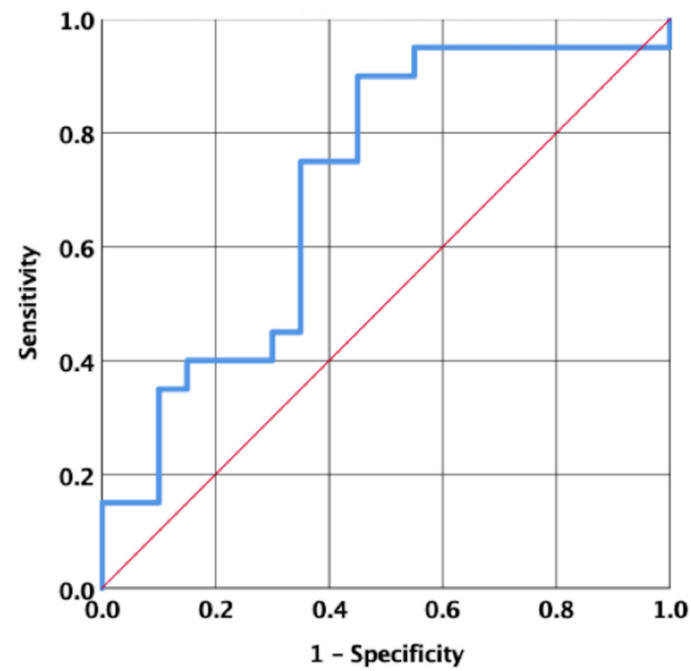

Figure 4. The receiver operating characteristic curve analysis. The receiver operating characteristic curve analysis of salivary conductivity is used to distinguish between different body fluid statuses (water restriction and rehydration statuses); $\mathrm{AUC}=0.707, p=0.025$. 


\section{Discussion}

The analytical data from this study suggest that salivary conductivity was significantly correlated with fluid status in healthy adults. Salivary conductivity reflected the acute changes in fluid status, especially during the rehydration process. This salivary biomarker may be added to the evaluation methods of fluid status. In addition, this study also found that the levels of serum copeptin and the fractional excretion of sodium were sensitive to the acute changes in fluid status. ROC curve analysis provides the criterion values of salivary conductivity for diagnosing dehydration.

According to Lacey et al. [22], there are two main mechanisms for the restoration of fluid balance in adults: decreased total body water and dehydration. First, increased serum osmolality stimulates the osmoreceptor and hypothalamus for the following regulation process. In contrast, decreased blood volume can activate the baroreceptor-mediated sympathetic nervous system and the renin-angiotensin-aldosterone system to maintain fluid status. Both mechanisms are attributed to the increased arginine vasopressin secretion, renal conservation, thirst sensation, and oral intake.

Many biomarkers have been described in the evaluation of fluid status in people with different clinical conditions. In a study of 18 volunteers, Popowski et al. [13] reported that serum osmolality can accurately identify the hydration state and is sensitive to changes in the hydration state during acute dehydration and rehydration. Decreased water intake resulted in increased serum osmolality, which has also been observed in other clinical studies [23]. Urine specific gravity and urine osmolality are also very sensitive to changes in hydration status, but these lag behind during rapid body fluid turnover. As such, they are only moderately correlated with serum osmolality during acute dehydration. The current consensus considers urine osmolality a valid biomarker for diagnosing dehydration [24-26].

Thirst intensity, assessed using the category and visual analog scales, was used to evaluate the subjective sensation of the fluid status of healthy individuals in daily life [27,28]. According to Davies et al. [29], changes in body weight can be used to estimate body fluid status in ill patients. However, total body weight is not suitable for monitoring the dynamic body fluid status [30,31]. Lemetais et al. [32] revealed that the level of copeptin was associated with fluid status.

In our study (Figure 2), serum osmolality, urine osmolality, urine specific gravity, thirst intensity category scale and thirst intensity visual analog scale increase after 12-h water restriction and decrease after water rehydration. Fractional excretion of sodium reveals a trend contrasting the other biomarkers above. More serum sodium was preserved by renal regulation to decreased loss of body water during the period of water restriction. The change of biomarkers for evaluation of fluid status in our study is compatible with previous studies. However, the concentration of serum copeptin increases after 12-h water restriction but does not change after water rehydration. It may indicate that serum copeptin does no change immediately during water supplement in the clinical practice.

Furthermore, urine osmolality and urine specific gravity were correlated with copeptin levels. Muñoz et al. [33] reported that salivary osmolality is the most accurate method among serum osmolality, salivary osmolality, urine osmolality, urine volume, and urine specific gravity for detecting dehydration. Several clinical studies have reported that salivary osmolality increased with progressive fluid depletion and dehydration [34-36]. In specific clinical conditions, such as hypertonic-hypervolemia dehydration, the sensitivity of salivary osmolality is nearly equal to the osmolality of urine in reflecting fluid status [35]. Currently, salivary osmolality may be a good biomarker for the evaluation of body fluid status [37].

In contrast, shorter laboratory turnaround times can prevent patients from being diagnosed [38]. In a prospective study of 166 patients, Moon et al. [39] reported that the median turnaround time (TAT) of routine biochemical tests was 36-57 min, depending on the month. Another prospective study of 81 patients in the emergency department revealed that the median TAT of urine analysis observed via a photometric analyzer was 
33 min [40]. Prolonged TAT may lead to delayed diagnosis and consequently, poor clinical outcomes. Therefore, early interventions for dehydration depend on the quick evaluation of the fluid status.

In this study, compared to the rehydration group, both objective and subjective data from the baseline status, including salivary conductivity, serum osmolality, urine osmolality, urine specific gravity, and the thirst intensity scales, tended to reveal the status of water depletion (Figure 3). Symptoms of early dehydration are not clear, and some may be too mild to present with obvious signs [41]. A symptomless water-deprived status should be considered. Neglected mild dehydration may prevent proper fluid intake in daily life.

Responsiveness to changes in fluid intake volume during hydration and rehydration of biomarkers is vital. According to current research, analysis of serum and urine samples can accurately reflect fluid status. However, prolonged TAT may cause poor outcomes; it may take about half to one hour from sample collection to presentation of the valid report [39,40]. Furthermore, an invasive procedure is necessary for blood sample collection. Suboptimal sample collection and transport can lead to incorrect diagnoses in clinical practice [42]. As for the thirst scale, both the categorical and visual analog scales were based on the subjective descriptions of the participants, which may be prone to evaluation bias. Such a subjective evaluation scale is limited by cognitive function and mental status [43].

The use of a portable device for monitoring salivary conduction can provide rapid, real-time, and straightforward laboratory data for the evaluation of fluid status. This specific salivary biomarker can be applied in many fields, such as in farmlands for farmers, pre-operation rooms for short-term fasting patients, sports fields for athletes, medical institutions for patients who have a potential risk of dehydration, and all healthy adults for monitoring fluid status in daily life. Salivary conduction can also provide recommendations to supplement fluid intake.

Finally, the limitations of this study included the small sample size that consisted only of adults. The process of dehydration in this study is a stress test. The clinical condition can be dramatic or unpredictable change during water restriction in children, the elder and patients with systemic disease. Under research ethics, we were prone to selecting the participants who with enough tolerance under the designed stress test in this study. In addition, the short observation period in this study led to the limited information that could have been used for further analysis. Further well-designed prospective studies are warranted to confirm our findings.

\section{Conclusions}

In summary, salivary conductivity is a rapid, real-time, and easy-to-administer screening tool for the evaluation of fluid status in healthy adults. It can be applied to our daily lives to prevent unexpected imbalances in body fluids. This portable monitoring system allows for a rapid and non-invasive method for assessing hydration status, reducing unnecessary medical expenses and preventing the complications of dehydration.

Supplementary Materials: The following are available online at https: / www.mdpi.com/article / 10.3390/jpm11060577/s1, Table S1: Different parameters for the evaluation of body fluid status in normal status, Table S2: Different parameters for the evaluation of body fluid status in water restriction, Table S3: Different parameters for the evaluation of body fluid status in rehydration status.

Author Contributions: Conceptualization, C.-H.C., Y.-P.L., C.-T.L. and. J.-T.Y.; methodology, C.-H.C., A.-T.L., Y.-P.L., C.-T.L. and. J.-T.Y.; software, Y.-P.L., Y.-H.T. and C.-T.L.; validation, Y.-P.L., Y.-H.T. and C.-T.L.; formal analysis, C.-H.C., H.-P.T., C.-W.T. and. J.-T.Y.; investigation, Y.-P.L., C.-T.L. and. J.-T.Y.; resources, Y.-H.T., C.-T.L. and. J.-T.Y.; data curation, C.-H.C., Y.-P.L., A.-T.L., H.-P.T., C.-W.T., C.-T.L. and. J.-T.Y.; writing-original draft preparation, C.-H.C. and Y.-P.L.; writing-review and editing, C.-T.L. and. J.-T.Y.; visualization, C.-T.L., and. J.-T.Y.; supervision, C.-T.L. and. J.-T.Y.; project administration, J.-T.Y.; funding acquisition, J.-T.Y. All authors have read and agreed to the published version of the manuscript. 
Funding: This research was supported by grants from the Chang Gung Medical Research Project to Yuan-Hsiung Tsai and Jen-Tsung Yang (CORPG6G0183, CORPG6G0211, CORPG6G0212, CORPG6G0213 and CORPG6G0233).

Institutional Review Board Statement: The study was conducted according to the guidelines of the Declaration of Helsinki, and approved by the Ethics Committee of Chang Gung Memorial Hospital (institutional review board number: 201700651B0).

Informed Consent Statement: Written informed consent was obtained from the patient(s) to publish this paper.

Data Availability Statement: The datasets used and analyzed in this study are available from the corresponding author upon reasonable request.

Conflicts of Interest: All authors declare no conflict of interest. The funders had no role in the design of the study; in the collection, analyses or interpretation of data; in the writing of the manuscript, or in the decision to publish the results.

\section{References}

1. Lier, H.; Bernhard, M.; Hossfeld, B. Hypovolemic and hemorrhagic shock. Anaesthesist 2018, 67, 225-244. [CrossRef]

2. Manz, F. Hydration and disease. J. Am. Coll. Nutr. 2007, 26, 535s-541s. [CrossRef]

3. Fortes, L.S.; Nascimento-Júnior, J.R.A.; Mortatti, A.L.; Lima-Júnior, D.; Ferreira, M.E.C. Effect of dehydration on passing decision making in soccer athletes. Res. Q. Exerc. Sport 2018, 89, 332-339. [CrossRef]

4. Hurley, S.W.; Arseth, H.A.; Johnson, A.K. Orexin neurons couple neural systems mediating fluid balance with motivation-related circuits. Behav. Neurosci. 2018, 132, 284-292. [CrossRef] [PubMed]

5. Patsalos, O.C.; Thoma, V. Water supplementation after dehydration improves judgment and decision-making performance. Psychol. Res. 2020, 84, 1223-1234. [CrossRef] [PubMed]

6. Sawka, M.N.; Burke, L.M.; Eichner, E.R.; Maughan, R.J.; Montain, S.J.; Stachenfeld, N.S. American College of Sports Medicine position stand. Exercise and fluid replacement. Med. Sci. Sports Exerc. 2007, 39, 377-390. [CrossRef]

7. Moghadamyeghaneh, Z.; Phelan, M.J.; Carmichael, J.C.; Mills, S.D.; Pigazzi, A.; Nguyen, N.T.; Stamos, M.J. Preoperative dehydration increases risk of postoperative acute renal failure in colon and rectal surgery. J. Gastrointest. Surg. 2014, 18, 2178-2185. [CrossRef] [PubMed]

8. Feehally, J.; Khosravi, M. Effects of acute and chronic hypohydration on kidney health and function. Nutr. Rev. 2015, 73 (Suppl. 2), 110-119. [CrossRef] [PubMed]

9. Elias, S.; Hoffman, R.; Saharov, G.; Brenner, B.; Nadir, Y. Dehydration as a possible cause of monthly variation in the incidence of venous thromboembolism. Clin. Appl. Thromb. Hemost. 2016, 22, 569-574. [CrossRef]

10. Fortes, M.B.; Owen, J.A.; Raymond-Barker, P.; Bishop, C.; Elghenzai, S.; Oliver, S.J.; Walsh, N.P. Is this elderly patient dehydrated? Diagnostic accuracy of hydration assessment using physical signs, urine, and saliva markers. J. Am. Med. Dir. Assoc. 2015, 16, 221-228. [CrossRef]

11. Hooper, L.; Abdelhamid, A.; Attreed, N.J.; Campbell, W.W.; Channell, A.M.; Chassagne, P.; Culp, K.R.; Fletcher, S.J.; Fortes, M.B.; Fuller, N.; et al. Clinical symptoms, signs and tests for identification of impending and current water-loss dehydration in older people. Cochrane Database Syst. Rev. 2015, 2015, Cd009647. [CrossRef]

12. Bunn, D.K.; Hooper, L. Signs and Symptoms of Low-Intake Dehydration Do Not Work in Older Care Home Residents-DRIE Diagnostic Accuracy Study. J. Am. Med. Dir. Assoc. 2019, 20,963-970. [CrossRef]

13. Popowski, L.A.; Oppliger, R.A.; Patrick Lambert, G.; Johnson, R.F.; Kim Johnson, A.; Gisolf, C.V. Blood and urinary measures of hydration status during progressive acute dehydration. Med. Sci. Sports Exerc. 2001, 33, 747-753. [CrossRef]

14. Cheuvront, S.N.; Ely, B.R.; Kenefick, R.W.; Sawka, M.N. Biological variation and diagnostic accuracy of dehydration assessment markers. Am. J. Clin. Nutr. 2010, 92, 565-573. [CrossRef]

15. Morgan, R.M.; Patterson, M.J.; Nimmo, M.A. Acute effects of dehydration on sweat composition in men during prolonged exercise in the heat. Acta Physiol. Scand. 2004, 182, 37-43. [CrossRef] [PubMed]

16. Fortes, M.B.; Diment, B.C.; Di Felice, U.; Gunn, A.E.; Kendall, J.L.; Esmaeelpour, M.; Walsh, N.P. Tear fluid osmolarity as a potential marker of hydration status. Med. Sci. Sports Exerc. 2011, 43, 1590-1597. [CrossRef] [PubMed]

17. Ely, B.R.; Cheuvront, S.N.; Kenefick, R.W.; Sawka, M.N. Limitations of salivary osmolality as a marker of hydration status. Med. Sci. Sports Exerc. 2011, 43, 1080-1084. [CrossRef] [PubMed]

18. Lu, Y.P.; Huang, J.W.; Lee, I.N.; Weng, R.C.; Lin, M.Y.; Yang, J.T.; Lin, C.T. A portable system to monitor saliva conductivity for dehydration diagnosis and kidney healthcare. Sci. Rep. 2019, 9, 14771. [CrossRef] [PubMed]

19. Thompson, D.A.; Campbell, R.G. Hunger in humans induced by 2-deoxy-D-glucose: Glucoprivic control of taste preference and food intake. Science 1977, 198, 1065-1068. [CrossRef]

20. Rolls, B.J.; Wood, R.J.; Rolls, E.T.; Lind, H.; Lind, W.; Ledingham, J.G. Thirst following water deprivation in humans. Am. J. Physiol. 1980, 239, R476-R482. [CrossRef] 
21. Martínez-Camblor, P.; Pardo-Fernández, J.C. The Youden index in the generalized receiver operating characteristic curve context. Int. J. Biostat. 2019, 15. [CrossRef]

22. Lacey, J.; Corbett, J.; Forni, L.; Hooper, L.; Hughes, F.; Minto, G.; Moss, C.; Price, S.; Whyte, G.; Woodcock, T.; et al. A multidisciplinary consensus on dehydration: Definitions, diagnostic methods and clinical implications. Ann. Med. 2019, 51, 232-251. [CrossRef] [PubMed]

23. Kanbay, M.; Yilmaz, S.; Dincer, N.; Ortiz, A.; Sag, A.A.; Covic, A.; Sánchez-Lozada, L.G.; Lanaspa, M.A.; Cherney, D.Z.I.; Johnson, R.J.; et al. Antidiuretic hormone and serum osmolarity physiology and related outcomes: What is old, what is new, and what is unknown? J. Clin. Endocrinol. Metab. 2019, 104, 5406-5420. [CrossRef] [PubMed]

24. Dias, F.C.; Boilesen, S.N.; Tahan, S.; Melli, L.C.; Morais, M.B. Prevalence of voluntary dehydration according to urine osmolarity in elementary school students in the metropolitan region of São Paulo, Brazil. Clinics (Sao Paulo) 2019, 74, e903. [CrossRef]

25. Bar-David, Y.; Urkin, J.; Kozminsky, E. The effect of voluntary dehydration on cognitive functions of elementary school children. Acta Paediatr. 2005, 94, 1667-1673. [CrossRef] [PubMed]

26. Armstrong, L.E.; Kavouras, S.A.; Walsh, N.P.; Roberts, W.O. Diagnosing dehydration? Blend evidence with clinical observations Curr. Opin. Clin. Nutr. Metab. Care 2016, 19, 434-438. [CrossRef]

27. Millard-Stafford, M.; Wendland, D.M.; O’Dea, N.K.; Norman, T.L. Thirst and hydration status in everyday life. Nutr. Rev. 2012, 70 (Suppl. 2), S147-S151. [CrossRef]

28. Armstrong, L.E.; Giersch, G.E.W.; Dunn, L.; Fiol, A.; Muñoz, C.X.; Lee, E.C. Inputs to thirst and drinking during water restriction and rehydration. Nutrients 2020, 12, 2554. [CrossRef]

29. Davies, H.; Leslie, G.; Jacob, E.; Morgan, D. Estimation of body fluid status by fluid balance and body weight in critically ill adult patients: A systematic review. Worldviews Evid. Based Nurs. 2019, 16, 470-477. [CrossRef]

30. Hamouti, N.; Del Coso, J.; Avila, A.; Mora-Rodriguez, R. Effects of athletes' muscle mass on urinary markers of hydration status. Eur. J. Appl. Physiol. 2010, 109, 213-219. [CrossRef]

31. Hamouti, N.; Del Coso, J.; Mora-Rodriguez, R. Comparison between blood and urinary fluid balance indices during dehydrating exercise and the subsequent hypohydration when fluid is not restored. Eur. J. Appl. Physiol. 2013, 113, 611-620. [CrossRef]

32. Lemetais, G.; Melander, O.; Vecchio, M.; Bottin, J.H.; Enhörning, S.; Perrier, E.T. Effect of increased water intake on plasma copeptin in healthy adults. Eur. J. Nutr. 2018, 57, 1883-1890. [CrossRef]

33. Muñoz, C.X.; Johnson, E.C.; Demartini, J.K.; Huggins, R.A.; McKenzie, A.L.; Casa, D.J.; Maresh, C.M.; Armstrong, L.E. Assessment of hydration biomarkers including salivary osmolality during passive and active dehydration. Eur. J. Clin. Nutr. 2013, 67, 1257-1263. [CrossRef] [PubMed]

34. Taylor, N.A.; van den Heuvel, A.M.; Kerry, P.; McGhee, S.; Peoples, G.E.; Brown, M.A.; Patterson, M.J. Observations on saliva osmolality during progressive dehydration and partial rehydration. Eur. J. Appl. Physiol. 2012, 112, 3227-3237. [CrossRef] [PubMed]

35. Walsh, N.P.; Laing, S.J.; Oliver, S.J.; Montague, J.C.; Walters, R.; Bilzon, J.L. Saliva parameters as potential indices of hydration status during acute dehydration. Med. Sci. Sports Exerc. 2004, 36, 1535-1542. [CrossRef] [PubMed]

36. Pross, N.; Demazières, A.; Girard, N.; Barnouin, R.; Santoro, F.; Chevillotte, E.; Klein, A.; Le Bellego, L. Influence of progressive fluid restriction on mood and physiological markers of dehydration in women. Br. J. Nutr. 2013, 109, 313-321. [CrossRef]

37. Smith, D.L.; Shalmiyeva, I.; Deblois, J.; Winke, M. Use of salivary osmolality to assess dehydration. Prehosp. Emerg. Care 2012, 16, 128-135. [CrossRef]

38. Rogers, B.B.; Shankar, P.; Jerris, R.C.; Kotzbauer, D.; Anderson, E.J.; Watson, J.R.; O’Brien, L.A.; Uwindatwa, F.; McNamara, K.; Bost, J.E. Impact of a rapid respiratory panel test on patient outcomes. Arch. Pathol. Lab. Med. 2015, 139, 636-641. [CrossRef] [PubMed]

39. Moon, S.Y.; Lee, H.S.; Park, M.S.; Kim, I.S.; Lee, S.M. Evaluation of the barricor tube in 28 routine chemical tests and its impact on turnaround time in an outpatient clinic. Ann. Lab. Med. 2021, 41, 277-284. [CrossRef]

40. Choi, K.; Chang, I.; Lee, J.C.; do Kyun, K.; Noh, S.; Ahn, H.; Cho, J.H.; Kwak, Y.H.; Kim, S.; Kim, H.C. Smartphone-based urine reagent strip test in the emergency department. Telemed. J. E Health 2016, 22, 534-540. [CrossRef]

41. Hooper, L.; Bunn, D.; Jimoh, F.O.; Fairweather-Tait, S.J. Water-loss dehydration and aging. Mech. Ageing Dev. 2014, 136-137, 50-58. [CrossRef] [PubMed]

42. Harr, K.E. Sample collection. Vet. Clin. N. Am. Exot. Anim. Pract. 2018, 21, 579-592. [CrossRef] [PubMed]

43. Shrout, P.E.; Stadler, G.; Lane, S.P.; McClure, M.J.; Jackson, G.L.; Clavél, F.D.; Iida, M.; Gleason, M.E.J.; Xu, J.H.; Bolger, N. Initial elevation bias in subjective reports. Proc. Natl. Acad. Sci. USA 2018, 115, E15-E23. [CrossRef] [PubMed] 